\title{
Prognostic significance of the number of tumors and aggressive surgical approach in colorectal cancer hepatic metastasis
}

\author{
Kun-Ming Chan ${ }^{1 *}$, Tsung-Han Wu ${ }^{1}$, Chih-Hsien Cheng ${ }^{1}$, Wei-Chen Lee ${ }^{1}$, Jy-Ming Chiang ${ }^{2}$, Jinn-Shiun Chen ${ }^{2}$ \\ and Jeng-Yi Wang ${ }^{2}$
}

\begin{abstract}
Background: Although liver resection (LR) for colorectal cancer (CRC) hepatic metastasis is the best strategy to improve patient outcomes, there are considerable concerns regarding the recurrence of CRC after LR. In this study, we investigated the prognostic indicators associated with CRC recurrence after LR for hepatic metastasis.

Methods: This is a retrospective review of patients who underwent curative LR for CRC hepatic metastasis between January 2008 and December 2012. The clinicopathological features and outcome parameters affecting prognosis were analyzed.

Results: A total of 332 LRs with curative intent were performed in 278 patients, of whom 168 (60.4\%) experienced CRC recurrence after the first LR, and 206 of the 332 LRs (62.0\%) developed CRC recurrence. A preoperative serum carcinoembryonic antigen level greater than $100 \mathrm{ng} / \mathrm{mL}$ and four or more metastatic tumor nodules were independent prognostic factors for $C R C$ recurrence after $L R$. The disease-free survival rate after $L R$ was significantly associated with the number of metastatic nodules. The patients who underwent surgical resection for recurrent CRC had favorable outcomes, with a five-year overall survival rate of $65.2 \%$.

Conclusion: The number of metastatic tumors significantly affects the outcomes of patients who undergo LR for CRC hepatic metastasis, indicating that a novel therapeutic strategy for patients at high risk may be required. However, favorable long-term outcomes are achievable through aggressive treatment with surgical resection of the recurrent CRC.
\end{abstract}

Keywords: Colorectal cancer, Hepatic metastasis, Liver resection, Outcome

\section{Background}

The liver is the most common site of distant spread of primary colorectal cancer (CRC), and over $50 \%$ of patients will develop hepatic metastasis during the course of their disease [1,2]. Liver resection (LR) is believed to provide the only chance of curative treatment, and has largely improved the long-term outcomes of these patients if the metastatic CRC is confined to the liver [2-4]. With the introduction of multidisciplinary treatment and the advancement of surgical management and chemotherapeutic

\footnotetext{
* Correspondence: chankunming@adm.cgmh.org.tw

'Department of General Surgery, Chang Gung Memorial Hospital at Linkou, Chang Gung University College of Medicine, 5 Fu-Hsing Street, Kwei-Shan Township, Taoyuan 33305, Taiwan

Full list of author information is available at the end of the article
}

agents, the five-year survival rate following LR with curative intent for CRC hepatic metastasis has been reported to be up to $60 \%$ in recently published studies [5-7]. Nevertheless, despite the excellent results of surgical resection for metastatic $\mathrm{CRC}$, it is estimated that more than half of the patients will still develop recurrence within two years $[8,9]$.

CRC is a common gastrointestinal malignancy worldwide, and has recently been reported to be the most common cancer in East Asian countries. LR is increasingly being used as the standard practice for CRC hepatic metastasis as well. Although numerous previous studies have reported prognostic factors capable of predicting the outcomes for CRC patients undergoing LR for hepatic metastasis [5,10-12], predictors for CRC 
recurrence following LR remains entirely elusive. Moreover, despite a growing experience and literature, it is still an issue of great concern. In the current study, we retrospectively reviewed our experience with LR for patients with hepatic metastasis from CRC with the aim of providing additional information in terms of the factors associated with the prognosis of the patients undergoing LR, as well as the outcomes of CRC recurrence after $L R$.

\section{Methods}

\section{Patients}

This study included patients with CRC hepatic metastasis who underwent LR with curative intent between January 2008 and December 2012 at Chang Gung Memorial Hospital Linkou Medical Center (Linkou, Taiwan). A retrospective review of all medical records was performed with approval of the Institutional Review Board of Chang Gung Memorial Hospital. Data from the medical records including clinical characteristics, surgical management and outcomes were analyzed.

\section{Liver resection for hepatic metastasis}

The clinical status of CRC and hepatic metastasis was thoroughly evaluated using appropriate imaging studies, including computed tomography (CT) scans of the abdominal and pelvic areas, and/or chest CT for all patients prior to surgery. Positron emission tomography (PET) or $\mathrm{PET} / \mathrm{CT}$ was not routinely performed, but was occasionally performed for the patients who had equivocal conventional imaging study results to confirm occult metastasis if indicated. The treatment for CRC hepatic metastasis was decided by consensus of the members of the multidisciplinary committee, which was comprised of liver surgeons, proctologists, oncologists, radiologists and interventional radiologists. Treatment options mainly depended on the tumor's characteristics and the patient's physical condition, and liver resection was always the preferred treatment for patients with resectable hepatic metastasis. Resectability of hepatic metastasis with a curative intent required complete resection of all hepatic metastatic lesions, and preservation of a sufficient volume of liver with adequate vascular inflow and outflow. The extent of LR was defined on the basis of Couinaud's classification. The patients with imaging evidence of concurrent unresectable extrahepatic metastasis were considered ineligible for LR.

\section{Follow-up after liver resection}

After LR, postoperative adjuvant chemotherapy was recommended for all patients, unless the patient's physical status was unsuitable for chemotherapy or they were unwilling to receive chemotherapy. The chemotherapeutic regimens mainly depended on the aggressiveness of the tumor characteristics, the patient's physical condition, availability of the chemotherapeutic regimens, and affordability of the chemotherapy drugs. The chemotherapeutic options were mostly fluorouracil plus leucovorin and a combination of options, including oxaliplatin, irinotecan, bevacizumab and cetuximab. Additionally, all patients were regularly followed up and monitored for CRC recurrence by measuring serum carcinoembryonic antigen (CEA) levels and liver ultrasonography one month after LR and every three months thereafter. CT and/or magnetic resonance imaging (MRI) was performed at yearly intervals or whenever CRC recurrence was suspected. Disease recurrence was determined by a tissue sample from either a biopsy or surgical resection confirming CRC, and/or by serial imaging examinations. All patients were followed up until death or the end of the study period. The strategy for the treatment of recurrent CRC after LR was the same as that for the initial management of CRC, and depended on the consensus of the multidisciplinary committee.

Table 1 Clinicopathological characteristics of the patients who underwent liver resection for colorectal cancer hepatic metastasis

\begin{tabular}{lcc}
\hline Characteristics & $\begin{array}{c}\text { Patients } \\
n=278\end{array}$ & $\begin{array}{c}\text { Liver resections } \\
n=332\end{array}$ \\
\hline
\end{tabular}

\begin{tabular}{lll}
\hline Age (years), median (range) $\quad 60.4(29.1$ to 88.0$)$ & 60.9 (29.1 to 88.0)
\end{tabular}

Gender

Male

Female

$186(66.9 \%)$

$225(67.8 \%)$

$92(33.1 \%)$

$107(32.2 \%)$

Primary tumor location

Colon

$178(64.0 \%)$

$206(62.0 \%)$

Rectum

$100(36.0 \%)$

$126(38.0 \%)$

Type of initial hepatic metastasis

$\begin{array}{lll}\text { Synchronous } & 153(55.0 \%) & 153(46.1 \%) \\ \text { Metachronous } & 125(45.0 \%) & 179(53.9 \%)\end{array}$

$\mathrm{CRC}$ recurrence after liver

resection

$\begin{array}{lcc}\text { Yes } & 168(60.4 \%) & 206(62.0 \%) \\ \text { No } & 110(39.6 \%) & 126(38.0 \%) \\ \begin{array}{l}\text { Surgical resection of CRC } \\ \text { recurrence }\end{array} & 61(36.3 \%)^{*} & 74(35.9 \%)^{*} \\ \text { inal patient status } & & \\ \text { Alive and CRC free } & 128(46.0 \%) & - \\ \text { Alive with recurrent CRC } & 62(22.3 \%) & - \\ \text { Died of CRC } & 79(28.4 \%) & - \\ \text { Died of other causes } & 6(2.2 \%) & 3(0.9 \%) \\ \text { Surgical mortality } & 3(1.1 \%) & -\end{array}$

CRC, colorectal cancer; * represents the percentage among CRC recurrence. 
Table 2 The clinicopathological factors affecting CRC recurrence of all liver resections for hepatic metastasis

\begin{tabular}{|c|c|c|c|c|c|c|}
\hline \multirow[t]{2}{*}{ Factors } & \multicolumn{4}{|c|}{ Univariate analysis } & \multicolumn{2}{|c|}{ Multivariate analysis } \\
\hline & $n$ & Medium RFS (m) & HR, $(95 \% \mathrm{Cl})$ & $P$-value & $\mathrm{HR},(95 \% \mathrm{Cl})$ & $P$-alue \\
\hline \multicolumn{7}{|l|}{ Age (years) } \\
\hline$<55$ & 108 & 12.9 & $1.16,(0.86$ to 1.55$)$ & 0.327 & - & - \\
\hline$\geq 55$ & 224 & 14.7 & 1 & & & \\
\hline \multicolumn{7}{|l|}{ Gender } \\
\hline Male & 225 & 15.1 & 1 & 0.608 & - & - \\
\hline Female & 107 & 11.2 & $1.08,(0.80$ to 1.45$)$ & & & \\
\hline \multicolumn{7}{|l|}{ Primary tumor } \\
\hline Colon & 206 & 15.1 & 1 & 0.232 & - & - \\
\hline Rectum & 126 & 12.0 & $1.11,(0.89$ to 1.57$)$ & & & \\
\hline \multicolumn{7}{|l|}{ Serum CEA (ng/mL) } \\
\hline$<100$ & 294 & 15.1 & 1 & $<0.0001$ & 1 & 0.001 \\
\hline$\geq 100$ & 38 & 6.3 & $3.15,(1.83$ to 5.44$)$ & & $2.06,(1.36$ to 3.11$)$ & \\
\hline \multicolumn{7}{|l|}{ Metastatic type } \\
\hline Synchronous & 153 & 14.8 & 1 & 0.757 & 1 & 0.744 \\
\hline Metachronous & 179 & 13.1 & $0.95,(0.72$ to 1.26$)$ & & $1.05,(0.79$ to 1.40$)$ & \\
\hline \multicolumn{7}{|l|}{ Number of tumors } \\
\hline$<4$ nodules & 285 & 15.4 & 1 & 0.001 & 1 & 0.041 \\
\hline$\geq 4$ nodules & 47 & 8.3 & 2.22 , (1.40 to 3.51$)$ & & $1.53,(1.02$ to 2.29$)$ & \\
\hline \multicolumn{7}{|c|}{ Maximum tumor size (cm) } \\
\hline$<5$ & 267 & 13.6 & 1.39, (0.99 to 1.95$)$ & 0.058 & $1.40,(0.95$ to 2.06$)$ & 0.088 \\
\hline$\geq 5$ & 65 & 21.7 & 1 & & 1 & \\
\hline \multicolumn{7}{|l|}{ Distribution of metastasis } \\
\hline Unilobar & 239 & 15.9 & 1 & 0.025 & 1 & 0.399 \\
\hline Bilobar & 93 & 9.7 & $1.43,(1.40$ to 1.98$)$ & & 1.16 , (0.82 to 1.63$)$ & \\
\hline \multicolumn{7}{|l|}{ Extent of liver resection } \\
\hline$<3$ segments & 262 & 14.6 & 1 & 0.751 & - & - \\
\hline$\geq 3$ segments & 70 & 13.1 & $0.95,(0.68$ to 1.32$)$ & & & \\
\hline \multicolumn{7}{|l|}{ Resection margin (mm) } \\
\hline$<0.5$ & 142 & 11.5 & $1.42,(1.08$ to 1.88$)$ & 0.012 & $1.28,(0.95$ to 1.71$)$ & 0.103 \\
\hline$\geq 0.5$ & 190 & 16.8 & 1 & & 1 & \\
\hline \multicolumn{7}{|l|}{ Histologic grade } \\
\hline Low-moderate grade & 321 & 14.4 & 1 & 0.112 & 1 & 0.237 \\
\hline High grade & 11 & 6.9 & 1.92, (0.86 to 4.28$)$ & & $1.50,(0.77$ to 2.94$)$ & \\
\hline \multicolumn{7}{|c|}{ Postoperative chemotherapy } \\
\hline Fluorouracil & 57 & 12.5 & $1.28,(0.85$ to 1.93$)$ & 0.326 & $1.19,(0.80$ to 1.76$)$ & 0.712 \\
\hline Oxaliplatin base & 140 & 16.8 & 1 & & 1 & \\
\hline Irinotecan base & 103 & 12.8 & $1.34,(0.85$ to 1.93$)$ & & $1.19,(0.85$ to 1.65$)$ & \\
\hline No & 32 & 13.6 & $1.00,(0.60$ to 1.67$)$ & & $1.15,(0.68$ to 1.95$)$ & \\
\hline \multicolumn{7}{|c|}{ Associated with bevacizumab } \\
\hline Yes & 46 & 17.0 & 1 & 0.496 & - & - \\
\hline No & 286 & 13.5 & $1.15,(0.77$ to 1.72$)$ & & & \\
\hline \multicolumn{7}{|c|}{ Associated with cetuximab } \\
\hline Yes & 6 & 7.4 & $1.80,(0.52$ to 6.25$)$ & 0.352 & - & - \\
\hline No & 326 & 14.4 & 1 & & & \\
\hline
\end{tabular}


Table 2 The clinicopathological factors affecting CRC recurrence of all liver resections for hepatic metastasis (Continued)

Chemotherapy cycles

\begin{tabular}{|c|c|c|c|c|c|c|}
\hline$\geq 6$ & 232 & 15.4 & 1 & 0.233 & - & - \\
\hline$<6$ & 100 & 9.7 & $1.21,(0.89$ to 1.65$)$ & & & \\
\hline
\end{tabular}

CEA, carcinoembryonic antigen; $\mathrm{Cl}$, confidence interval; $\mathrm{CRC}$, colorectal cancer; $\mathrm{HR}$, hazard ratio; $\mathrm{RFS}$, recurrence free survival.

\section{Statistical analysis}

All statistical analyses were performed using SPSS statistical software version 17.0 (SPSS, Inc., Chicago, IL, USA) and Prism 5.0 (GraphPad Software, San Diego, CA, USA) for Windows. The end-point outcome measures were recurrence-free survival (RFS) and overall survival (OS). RFS was defined as the date of each LR to the date of detected CRC recurrence or the date of the last follow-up if there was no CRC recurrence. OS was defined as the date of the first LR to the date of death or the date of the last follow-up. Survival analysis was conducted using the KaplanMeier method. Variables were analyzed by multivariate analysis using a Cox regression proportional hazards model to identify the factors influencing RFS on the basis of each LR. An optimal cutoff value for continuous variables was determined by receiver-operating characteristic (ROC) curve analysis. All significant prognostic factors determined by univariate analysis and important clinical variables were then entered into multivariate analysis. Statistical significance was set at a $P$-value of less than 0.05 .

\section{Results}

\section{Clinical characteristics of the patients}

A total of 332 LRs with curative intent were performed in 278 patients in this study. Of these patients, 186 (66.9\%) were men and $92(33.1 \%)$ were women, and the median age at the time of the first LR was 60.4 years (range, 29 to 88 years). After the first LR, the median follow-up period for the included patients was 23.8 months (range, 2 days to 108 months). Table 1 summarizes the clinical characteristics of the patients who underwent LR for CRC hepatic metastasis. The primary malignancy was located in the colon in $64 \%$ of the patients and $62 \%$ of the LRs. During follow-up, 168 patients (60.4\%) experienced CRC recurrence after the first LR, and 206 of the 332 LRs (62.0\%) developed CRC recurrence. Of the 168 patients with CRC recurrence, 61 (36.3\%) underwent surgical resection for the CRC recurrence, and 74 (35.9\%) surgical resections were performed for the 206 cases of CRC recurrence after LR. There were three cases of surgery-related mortality, and the mortality rates were $1.1 \%$ and $0.9 \%$ for all patients and the LRs, respectively.

\section{Recurrence after liver resection of hepatic metastasis}

Among the 332 LRs, the prognostic factors affecting CRC recurrence after LR were further analyzed and are summarized in Table 2. Univariate analysis identified the following five factors: preoperative serum CEA level, number of tumors, maximum tumor size, distribution of hepatic metastasis, and distance of resection margins. However, multivariate regression analysis of the prognostic factors showed that a preoperative serum CEA level $\geq 100 \mathrm{ng} / \mathrm{mL}(P=0.0001$, hazard ratio $(\mathrm{HR})=$ 2.06) and four or more tumor nodules $(P=0.041, \mathrm{HR}=$ 1.53) were independent prognostic factors of CRC recurrence following LR for hepatic metastasis.

Of the 168 patients who developed CRC recurrence after LR, 206 cases of CRC recurrence, including 143 $(69.4 \%)$ at a single anatomic site and 63 (30.6\%) at multiple anatomic sites or systemic spreading, were detected. Table 3 summarizes the location of CRC recurrence and the surgical management; 74 surgical resections including 54 repeat LRs were performed for 61 patients accounting for $35.9 \%$ of the LRs with CRC recurrence and $36.3 \%$ of patients with CRC recurrence, respectively. With regards to the LRs, 44 patients received multiple LRs, and 2 of them underwent up to

Table 3 CRC recurrence and surgical resection of recurrent lesions

\begin{tabular}{lcc}
\hline Recurrent features & CRC recurrence $^{\dagger}$ & Surgical resection $^{*}$ \\
\hline Number of patients & 168 & 61 \\
Location of recurrence & & \\
Single anatomic site & & $2(2.7 \%)$ \\
Abdominal wall & $16(7.8 \%)$ & $4(5.4 \%)$ \\
Intraabdominal mass & $90(43.7 \%)$ & $53(71.6 \%)$ \\
Liver & $29(14.1 \%)$ & $12(16.2 \%)$ \\
Lung & $3(1.4 \%)$ & $2(2.7 \%)$ \\
Brain & $3(1.4 \%)$ & $0(0 \%)$ \\
Bone & & $1(1.3 \%)$ \\
Multiple anatomic sites & $35(17.0 \%)$ & $0(0 \%)$ \\
Liver and lung & $28(13.6 \%)$ & 74 surgical resections \\
Systemic spreading & 206 recurrences & \\
Total & &
\end{tabular}

CRC, colorectal cancer; ${ }^{\dagger}$ percentages represent the ratio among total recurrences;

*Percentages represent the ratio among total surgical resections. 
four LRs. Overall, 88 patients (31.7\%) died, 62 (22.3\%) were alive with CRC recurrence and 128 (46.0\%) were alive without evidence of CRC at the end of the study period (Figure 1).

\section{Survival analysis of the patients}

During the follow-up period, the median time of CRC recurrence after LR was 10.3 months, and the three- and five-year RFS rates were $25.5 \%$ and $20.8 \%$, respectively. The median time of survival for all patients $(n=278)$ after the first LR was 23.7 months, with three- and fiveyear OS rates of $60.4 \%$ and $52.1 \%$, respectively (Figure 2). Of those with CRC recurrence, the median survival after the first detection of recurrence was 14.4 months. The survival curve of the patients who underwent surgical resection for recurrent CRC was better than that of the patients who did not undergo surgical resection for recurrent CRC. The three-year survival rates after CRC recurrence were $60.0 \%$ and $16.8 \%$ for the patients with and without surgical resection, respectively (Figure 3A, $P<0.0001)$. Moreover, the five-year OS rate of the patients who underwent surgical resection for CRC recurrence increased to $65.2 \%$ after the first LR, whereas the five-year OS rate of the patients who did not undergo surgical resection for CRC recurrence was only $16.0 \%$ (Figure 3B, $P<0.0001$ ).

With regards to the number of metastatic tumors, the RFS of the patients was significantly associated with the number of metastatic nodules in the liver. The results showed that patients with a solitary metastatic tumor had a better survival curve, and the five-year RFS rate was $28.8 \%$. As the number of tumor nodules increased, the actuarial RFS showed a significant decrease. Patients with four or more hepatic metastatic tumor nodules had the worst outcomes, with a five-year RFS rate of less than $10 \%$ (Figure $4, P=0.002$ ).

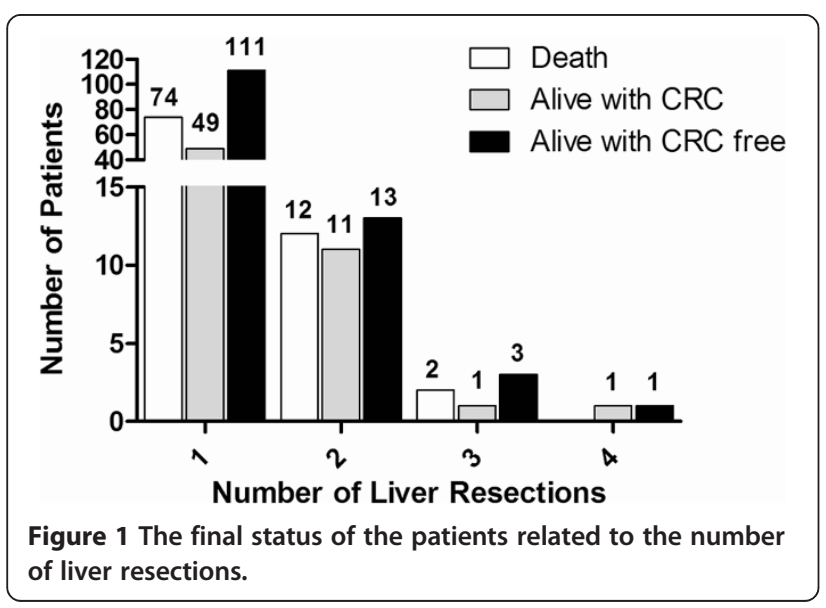

\section{Discussion and conclusion}

Liver resection currently offers the best chance of survival and potential cure for patients with CRC hepatic metastasis, and numerous reports have demonstrated long-term survival benefits [5-7]. Along with advances in preoperative preparation, both resectability and OS of patients with CRC hepatic metastasis have shown remarkable improvements [13-15]. However, similar to patients who undergo surgical resection for primary cancer, CRC recurrence after LR for hepatic metastasis remains a concern worldwide. In this study, we found that the rate of cancer recurrence was still very high, and involved nearly $60 \%$ of the patients after LR for hepatic metastasis from CRC. However, the results also demonstrated that aggressive surgical resection for recurrent $\mathrm{CRC}$ was beneficial.

The treatment strategies regarding hepatic metastasis from CRC have changed along with advancements in systemic therapy in the last decade. Recent evidence has demonstrated that systemic chemotherapy contributes to improvements in OS in patients with hepatic metastasis from CRC [16-18], and that it is effective even as neoadjuvant therapy [19]. Although numerous factors probably affect prolonging patient survival, the use of chemotherapy clearly plays a key role. However, the importance of postoperative adjuvant chemotherapy was not found in this study. A possible explanation could be that the adjuvant chemotherapy regimens in our patients were not identical, and comparisons of patients grouped by differing chemotherapeutic regimens may have been limited by the small number of patients in each group. Unfortunately, no consensus currently exists regarding which therapeutic protocol is the best for the prevention of CRC recurrence after LR, and further studies to clarify the effect of specific postoperative adjuvant chemotherapy regimens on RFS are required.

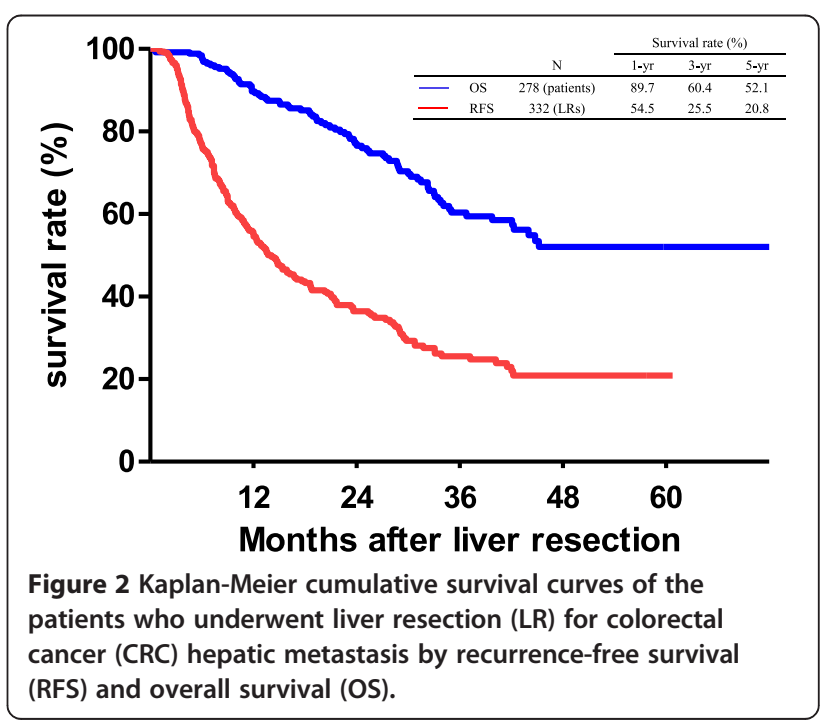




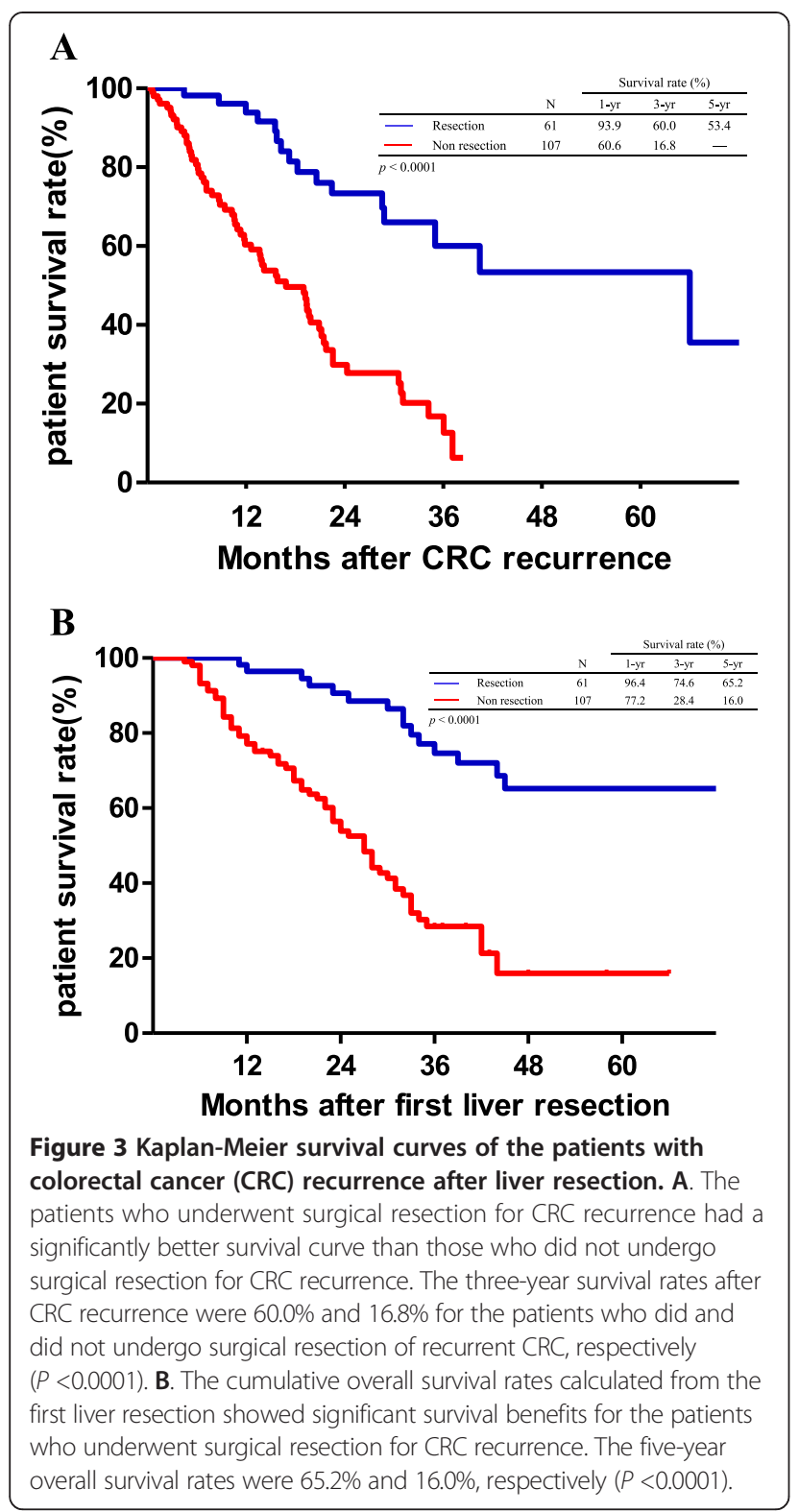

A number of previous reports have shown that several prognostic factors affect the outcomes of patients who undergo LR for hepatic metastasis from CRC, and similar factors were also noted in this study. The presence of multiple hepatic metastatic tumors seems to be a very important risk factor for CRC recurrence after LR $[11,15]$. Patients with multiple hepatic metastases, and specifically more than four tumor nodules, have been reported to be associated with a poor prognosis, and many surgeons are therefore reluctant to perform LR for these patients. Nevertheless, several studies have indicated that long-term survival is achievable after LR for multiple CRC hepatic metastases [20-22]. Furthermore, the safety of hepatic resection and more

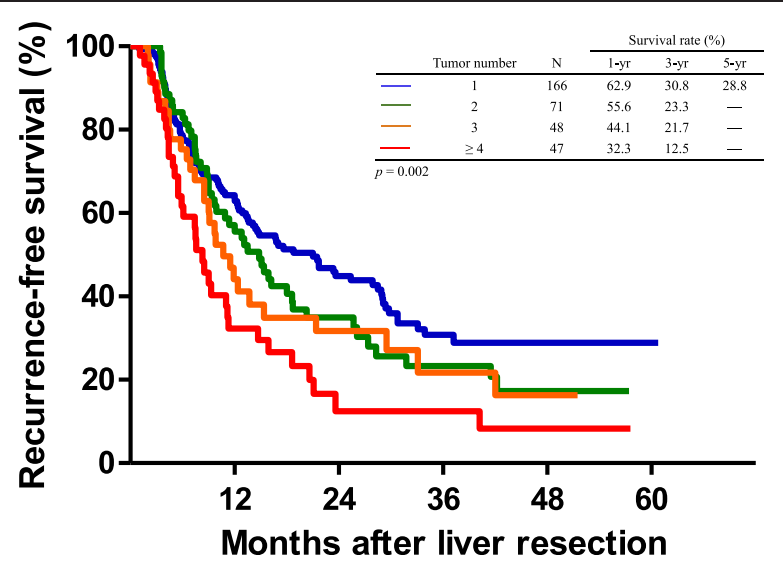

Figure 4 The recurrence-free survival (RFS) curves of the patients after liver resection in terms of the number of hepatic metastatic tumors. The patients with solitary metastatic tumors had the best RFS curve, and the RFS curves became worse as the number of tumor nodules increased $(P=0.002)$.

effective adjuvant chemotherapy also support the concept of an aggressive surgical approach for patients with multiple CRC hepatic metastases. Due to the lack of other potentially curative alternatives, the presence of multiple hepatic metastases should not be considered as a contraindication for LR.

Surgical resection of metastatic lesions with curative intent is currently the treatment of choice for several malignancies [23-25], including for patients with recurrence after LR for CRC hepatic metastasis $[26,27]$. Our results also showed that surgical resection of isolated recurrent lesions was beneficial in selected patients who underwent LR for CRC hepatic metastasis. Although the prognosis of patients who are suitable for surgical resection may be better than for patients who are ineligible for surgical resection, an aggressive attitude in terms of surgical resection still seems to be beneficial. As shown in the current study, many of the patients were alive without CRC recurrence after multiple LRs. Moreover, sequential resection with curative intent for multiple metastases in various anatomic sites may also offer favorable survival outcomes.

Taken together, despite distant metastasis and the clinical indication as a terminal-stage cancer, CRC is one of the few malignancies for which patients with metastasis confined to a single organ may obtain long-term survival through multidisciplinary treatment. However, CRC recurrence remains a problem that affects more than half of the patients who undergo LR for hepatic metastasis. Due to the beneficial results of surgical resection for recurrent lesions, it is essential to regularly and frequently follow-up patients in the first few years after LR to 
ensure the early detection of CRC recurrence at a resectable stage. In addition, to achieve better long-term outcomes for patients with CRC and effectively treat hepatic metastasis, the development of a treatment protocol that involves surgery and chemotherapeutic regimens is indicated.

\section{Abbreviations}

CEA: Carcinoembryonic antigen; CT: Computed tomography; CRC: Colorectal cancer HR, Hazard ratio; LR: Liver resection; OS: Overall survival; PET: Positron emission tomography; RFS: Recurrence-free survival.

\section{Competing interests}

There was no financial support for this research and publication, and the authors have no conflicts of interest.

\section{Authors' contributions}

KMC carried out the study and wrote the paper. THW, CHC, WCL, JMC, JSC, JYW participated in the collection of data. All authors read and approved the final manuscript.

\section{Acknowledgements}

This study was partly supported by grants from the Chang Gung Medical Research Program (CMRPG3A1393).

\section{Author details}

'Department of General Surgery, Chang Gung Memorial Hospital at Linkou, Chang Gung University College of Medicine, 5 Fu-Hsing Street, Kwei-Shan Township, Taoyuan 33305, Taiwan. ${ }^{2}$ Department of Colorectal Surgery, Chang Gung Memorial Hospital at Linkou, Chang Gung University College of Medicine, Taoyuan, Taiwan.

Received: 11 March 2014 Accepted: 6 May 2014

Published: 21 May 2014

\section{References}

1. Nordlinger B, Van Cutsem E, Gruenberger T, Glimelius B, Poston G, Rougier P, Sobrero A, Ychou M, European Colorectal Metastases Treatment Group; Sixth International Colorectal Liver Metastases Workshop: Combination of surgery and chemotherapy and the role of targeted agents in the treatment of patients with colorectal liver metastases: recommendations from an expert panel. Ann Oncol 2009, 20:985-992.

2. Manfredi S, Lepage C, Hatem C, Coatmeur O, Faivre J, Bouvier AM: Epidemiology and management of liver metastases from colorectal cancer. Ann Surg 2006, 244:254-259.

3. Simmonds PC, Primrose JN, Colquitt JL, Garden OJ, Poston GJ, Rees M: Surgical resection of hepatic metastases from colorectal cancer: a systematic review of published studies. Br I Cancer 2006, 94:982-999.

4. Garden OJ, Rees M, Poston GJ, Mirza D, Saunders M, Ledermann J, Primrose JN, Parks RW: Guidelines for resection of colorectal cancer liver metastases. Gut 2006, 55(Suppl 3):iii -iii8.

5. Rees $\mathrm{M}$, Tekkis PP, Welsh FK, O'Rourke T, John TG: Evaluation of long-term survival after hepatic resection for metastatic colorectal cancer: a multifactorial model of 929 patients. Ann Surg 2008, 247:125-135.

6. Fernandez FG, Drebin JA, Linehan DC, Dehdashti F, Siegel BA, Strasberg SM: Five-year survival after resection of hepatic metastases from colorectal cancer in patients screened by positron emission tomography with F-18 fluorodeoxyglucose (FDG-PET). Ann Surg 2004, 240:438-447. discussion 447-450.

7. Choti MA, Sitzmann JV, Tiburi MF, Sumetchotimetha W, Rangsin R, Schulick RD, Lillemoe KD, Yeo CJ, Cameron JL: Trends in long-term survival following liver resection for hepatic colorectal metastases. Ann Surg 2002, 235:759-766.

8. de Jong MC, Pulitano C, Ribero D, Strub J, Mentha G, Schulick RD, Choti MA, Aldrighetti L, Capussotti L, Pawlik TM: Rates and patterns of recurrence following curative intent surgery for colorectal liver metastasis: an international multi-institutional analysis of 1669 patients. Ann Surg 2009, 250:440-448.
9. D'Angelica M, Kornprat P, Gonen M, DeMatteo RP, Fong Y, Blumgart LH, Jarnagin WR: Effect on outcome of recurrence patterns after hepatectomy for colorectal metastases. Ann Surg Oncol 2011, 18:1096-1103.

10. Ueno H, Mochizuki H, Hashiguchi Y, Hatsuse K, Fujimoto H, Hase K: Predictors of extrahepatic recurrence after resection of colorectal liver metastases. Br J Surg 2004, 91:327-333.

11. Viganò L, Capussotti L, Lapointe R, Barroso E, Hubert C, Giuliante F, ljzermans JN, Mirza DF, Elias D, Adam R: Early recurrence after liver resection for colorectal metastases: risk factors, prognosis, and treatment. A LiverMetSurvey-based study of 6,025 patients. Ann Surg Oncol 2014, 21:1276-1286.

12. Spolverato G, Ejaz A, Azad N, Pawlik TM: Surgery for colorectal liver metastases: the evolution of determining prognosis. World J Gastrointest Oncol 2013, 5:207-221.

13. Adam R, Delvart V, Pascal G, Valeanu A, Castaing D, Azoulay D, Giacchetti S, Paule B, Kunstlinger F, Ghémard O, Levi F, Bismuth H: Rescue surgery for unresectable colorectal liver metastases downstaged by chemotherapy: a model to predict long-term survival. Ann Surg 2004, 240:644-657. discussion 657-658.

14. Capussotti L, Muratore A, Baracchi F, Lelong B, Ferrero A, Regge D, Delpero $J R$ : Portal vein ligation as an efficient method of increasing the future liver remnant volume in the surgical treatment of colorectal metastases. Arch Surg 2008, 143:978-982. discussion 982.

15. Chan KM, Chiang JM, Lee CF, Yu MC, Lee WC, Chen JS, Wang JY: Outcomes of resection for colorectal cancer hepatic metastases stratified by evolving eras of treatment. World I Surg Oncol 2011, 9:174.

16. Nordlinger B, Sorbye $H$, Glimelius B, Poston GJ, Schlag PM, Rougier P, Bechstein WO, Primrose JN, Walpole ET, Finch-Jones M, Jaeck D, Mirza D, Parks RW, Mauer M, Tanis E, Van Cutsem E, Scheithauer W, Gruenberger T, EORTC Gastro-Intestinal Tract Cancer Group; Cancer Research UK; Arbeitsgruppe Lebermetastasen und-tumoren in der Chirurgischen Arbeitsgemeinschaft Onkologie (ALM-CAO); Australasian Gastro-Intestinal Trials Group (AGITG); Fédération Francophone de Cancérologie Digestive (FFCD): Perioperative FOLFOX4 chemotherapy and surgery versus surgery alone for resectable liver metastases from colorectal cancer (EORTC 40983): long-term results of a randomised, controlled, phase 3 trial. Lancet Oncol 2013, 14:1208-1215.

17. Mitry E, Fields AL, Bleiberg H, Labianca R, Portier G, Tu D, Nitti D, Torri V, Elias D, O'Callaghan C, Langer B, Martignoni G, Bouché O, Lazorthes F, Van Cutsem E, Bedenne L, Moore MJ, Rougier P: Adjuvant chemotherapy after potentially curative resection of metastases from colorectal cancer: a pooled analysis of two randomized trials. J Clin Oncol 2008, 26:4906-4911.

18. Elias D, Goere D, Boige V, Kohneh-Sharhi N, Malka D, Tomasic G, Dromain C, Ducreux M: Outcome of posthepatectomy-missing colorectal liver metastases after complete response to chemotherapy: impact of adjuvant intra-arterial hepatic oxaliplatin. Ann Surg Oncol 2007, 14:3188-3194.

19. Chiappa A, Bertani E, Makuuchi M, Zbar AP, Contino G, Viale G, Pruneri G, Bellomi M, Della Vigna P, Zampino MG, Fazio N, Travaini ML, Trifirò G, Corbellini $C$, Andreoni B: Neoadjuvant chemotherapy followed by hepatectomy for primarily resectable colorectal cancer liver metastases. Hepatogastroenterology 2009, 56:829-834.

20. Kornprat $P$, Jarnagin $W R$, Gonen $M$, DeMatteo RP, Fong $Y$, Blumgart $L H$, D'Angelica M: Outcome after hepatectomy for multiple (four or more) colorectal metastases in the era of effective chemotherapy. Ann Surg Oncol 2007, 14:1151-1160.

21. Bolton JS, Fuhrman GM: Survival after resection of multiple bilobar hepatic metastases from colorectal carcinoma. Ann Surg 2000, 231:743-751.

22. Ercolani G, Grazi GL, Ravaioli M, Cescon M, Gardini A, Varotti G, Del Gaudio M, Nardo B, Cavallari A: Liver resection for multiple colorectal metastases: influence of parenchymal involvement and total tumor volume, vs number or location, on long-term survival. Arch Surg 2002, 137:1187-1192.

23. Assouad J, Petkova B, Berna P, Dujon A, Foucault C, Riquet M: Renal cell carcinoma lung metastases surgery: pathologic findings and prognostic factors. Ann Thorac Surg 2007, 84:1114-1120.

24. Ollila DW: Complete metastasectomy in patients with stage IV metastatic melanoma. Lancet Oncol 2006, 7:919-924.

25. Chan KM, Yu MC, Wu TJ, Lee CF, Chen TC, Lee WC, Chen MF: Efficacy of surgical resection in management of isolated extrahepatic metastases of hepatocellular carcinoma. World J Gastroenterol 2009, 15:5481-5488. 
26. Shaw IM, Rees $M$, Welsh FK, Bygrave $S$, John TG: Repeat hepatic resection for recurrent colorectal liver metastases is associated with favourable long-term survival. Br J Surg 2006, 93:457-464.

27. Wicherts DA, de Haas RJ, Salloum C, Andreani P, Pascal G, Sotirov D, Adam R, Castaing D, Azoulay D: Repeat hepatectomy for recurrent colorectal metastases. Br J Surg 2013, 100:808-818.

doi:10.1186/1477-7819-12-155

Cite this article as: Chan et al:: Prognostic significance of the number of tumors and aggressive surgical approach in colorectal cancer hepatic metastasis. World Journal of Surgical Oncology 2014 12:155.

\section{Submit your next manuscript to BioMed Central and take full advantage of:}

- Convenient online submission

- Thorough peer review

- No space constraints or color figure charges

- Immediate publication on acceptance

- Inclusion in PubMed, CAS, Scopus and Google Scholar

- Research which is freely available for redistribution 